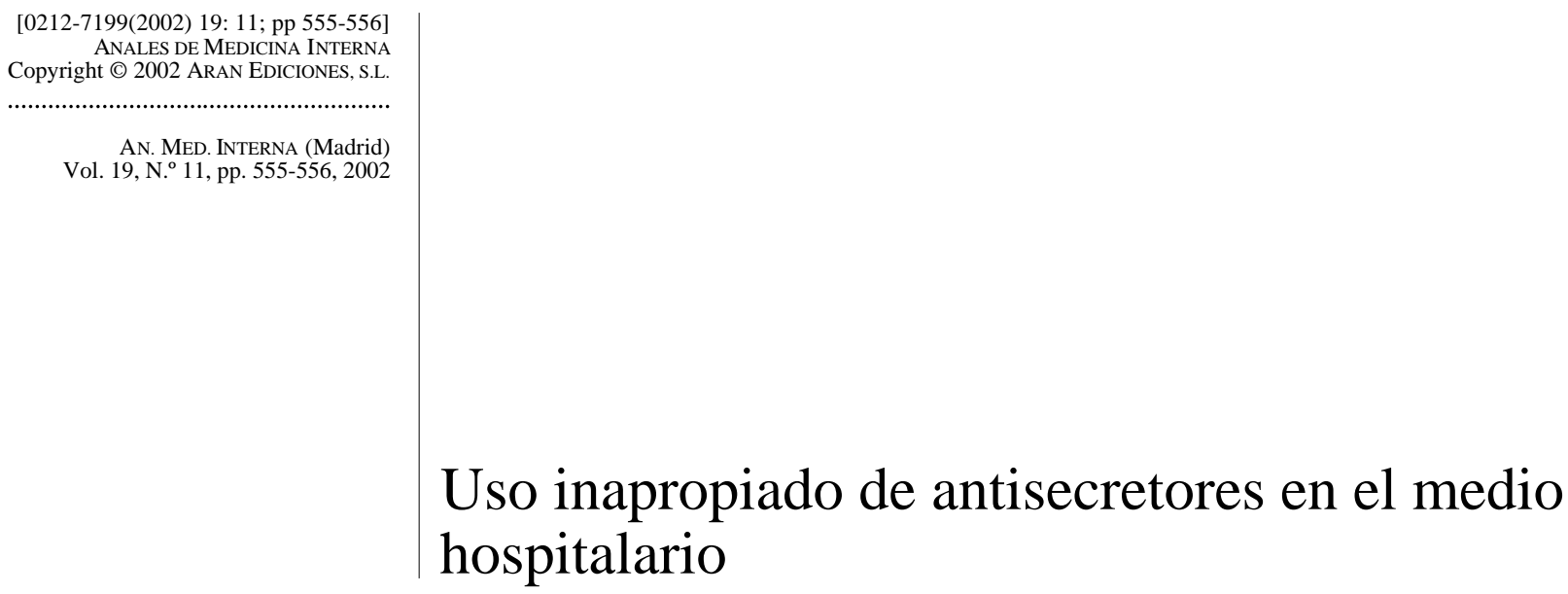

C. Taxonera Samsó. Uso inapropiado de antisecretores en el medio hospitalario. An Med Interna (Madrid) 2002; 19: 555-556.

Los antagonistas de los receptores $\mathrm{H} 2$ (anti-H2) son fármacos generalmente bien tolerados y seguros, con una tasa de efectos secundarios (habitualmente leves y reversibles) inferior al $4 \%$. Su comercialización supuso una revolución en enfermedades relacionadas con el ácido gástrico, en especial en la úlcera péptica, y con ciertas limitaciones en la enfermedad por reflujo gastroesofágico (ERGE). Constituían los fármacos de elección en el tratamiento en fase aguda de la úlcera gástrica y duodenal, así como en los pacientes en los que estaba indicado un tratamiento de mantenimiento. Los anti-H2 son útiles en la dispepsia funcional "tipo ulcerosa" y la gastritis y duodenitis erosiva.

La incorporación al arsenal terapéutico de los inhibidores de la bomba de protones (IBP) incrementa los beneficios ya obtenidos con los anti-H2. Se trata de fármacos que muestran también un buen perfil de seguridad con menos de un 5\% de efectos secundarios, generalmente leves y reversibles. Los IBP producen una mayor inhibición de la secreción ácida gástrica, que incluye la secreción ácida estimulada por la comida (la cual los anti-H2 no frenan adecuadamente). Estudios elegantes demostraron en su momento que cuanto mayor es el efecto antisecretor más úlceras pépticas curan y lo hacen más rápidamente (1). En la ERGE, en especial severa, la respuesta depende también de la profundidad de la antisecreción. Es por ello que en esta entidad los IBP son los fármacos de elección, aunque los anti-H2 pueden ser útiles en los casos más leves. Los IBP permiten también controlar (con mejor eficacia que los anti-H2) los síntomas ácido dependientes en el síndrome de Zollinger-Ellison (2).

En la actualidad se reconoce que el Helicobacter pylori es, seguido del consumo de AINEs, la etiología más frecuente de la úlcera péptica. Ello ha inducido un cambio en el uso de antisecretores en esta entidad. En el momento actual no es correcto un tratamiento de mantenimiento en pacientes con úlcera péptica e infectados por Helicobacter pylori. Solo en pacientes con úlcera Helicobacter pylori negativos y con recidivas o complicaciones múltiples puede aceptarse un mantenimiento con antisecretores. En la úlcera péptica Helicobacter pylori positiva en fase aguda o remota el tratamiento erradicador es de elección. Si la úlcera se presenta sin complicaciones no es preciso administrar antisecretores al finalizar dicho tratamiento erradicador. Los IBP junto con dos antibióticos (en ausencia de alergias claritromicina y amoxicilina) constituyen la pauta erradicadora de elección en nuestro medio.

La toma de AINEs constituye la segunda causa de úlcera péptica. Los IBP son, por número de pacientes tratados y por su perfil de tolerancia, los fármacos de elección en la profilaxis de lesiones asociadas a consumo de AINEs $(3,4)$. La indicación de profilaxis está limitada a pacientes con alto riesgo (intolerancia previa a AINEs, historia de úlcera o hemorragia digestiva alta asociada o no a AINEs, enfermedades concomitantes severas y edad avanzada). La alternativa la constituye el uso de inhibidores específicos de la isoenzima ciclooxigenasa 2, que por ser menos lesivos no precisan de profilaxis (salvo en casos de úlcera péptica previa Helicobacter pylori positiva). En pacientes que reciben AINEs y sin factores de riesgo la profilaxis con IBP no está indicada por no ser costeefectiva.

Los IBP son también útiles en test diagnósticos o terapéuticos en el dolor torácico de origen no cardiaco (5) o len las manifestaciones supraesofágicas de la ERGE, en especial la laringitis posterior.

En cuanto a indicaciones de los antisecretores a usar en el medio hospitalario están la hemorragia digestiva alta (HDA) y la profilaxis de úlceras de estrés. En la HDA por úlcera péptica los anti-H2 e IBP a dosis intermitentes no disminuyen la tasa de resangrado ni la mortalidad, pero su uso está avalado porque forma parte del tratamiento de cicatrización del nicho ulceroso. Los IBP a dosis masiva y en infusión continua disminuyen la tasa de resangrado en alguna serie (6). En lo referente a las úlceras de stress la profilaxis con antisecretores solo está indicada en pacientes críticos, en especial con ventilación mecánica y coagulopatia y grandes quemados (7).

Por todo lo dicho los antisecretores son fármacos seguros y con una gran utilidad en diversas entidades en áreas no solo terapéuticas sino también con fines diagnósticos y profilácticos. Ello puede inducir un uso adecuado pero también por su bondad un uso indiscriminado y excesivo que más que beneficio puede acarrear complicaciones y un gasto no justificado.

En ese sentido, en este número, Noguerado Asensio et 
al publican un interesante trabajo en el que valoran el uso de antisecretores en el medio hospitalario (8). Las indicaciones admitidas como correctas son amplias e incluyen la profilaxis de lesiones por AINEs, lo cual parece razonable dado que los pacientes tienen una media de edad avanzada e ingresan por patologías severas. Un $72,2 \%$ de los pacientes ingresados en planta reciben antisecretores durante el ingreso en planta, sin estar este tratamiento correctamente indicado en casi 3/4 partes de los casos. La causa más frecuente que motiva la utilización incorrecta de antisecretores es desconocida (el fármaco se prescribe sin dar razones), y lo más probable es que la indicación se realizara como profilaxis de lesiones en pacientes con bajo riesgo y que no toman AINEs. Le sigue en frecuencia el uso de corticoides, aunque es conocido que no son fármacos ulcerogénicos y no está indicada la profilaxis salvo que se asocien a AINEs. Entre las indicaciones incorrectas destaca la pancreatitis aguda: en esta entidad sigue siendo frecuente la administración de anti-H2, en especial ranitidina, sin ninguna base científica (9).

Del análisis del trabajo se extrae un dato interesante: aunque en muchos casos la indicación incorrecta del antisecretor se establece en urgencias es en la planta (a pesar de que en este lugar se dispone más tiempo y generalmente los tratamientos son supervisados por un staff) donde se alcanza la cota máxima de tratamientos incorrectos. Otro hecho a destacar es que una vez se indica el antisecretor este es difícil de retirar, por lo que con frecuencia se mantiene la prescripción al alta.

El interés del trabajo de Noguerado Asensio et al (8) reside en que valora la calidad de la prescripción de un grupo de fármacos en apariencia bien conocidos en su medio hospitalario. Ello constituye un esfuerzo de autoevaluación en el sentido de desarrollar mecanismos de información que permitan conocer si el funcionamiento en la prescripción de fármacos es adecuado o debe mejorarse.

El desarrollo de guías o protocolos de utilización de fármacos es la mejor manera de conseguir una prescripción correcta en base a la mejor evidencia y en función de las posibilidades del medio (10). Lo que objetiva este trabajo, y algún otro que obtiene similares resultados (11), es que se produce un uso excesivo e incorrecto de antisecretores en el medio hospitalario. Ello puede acarrear efectos secundarios y sin duda incrementa de manera injustificada el gasto farmacéutico. Parece por ello deseable el desarrollo e implantación de guías terapéuticas para un uso adecuado de antisecretores en el medio hospitalario en el que desarrollemos nuestra labor.

\section{TAXONERA SAMSÓ}

Servicio de Aparato Digestivo. Hospital Clínico San Carlos. Madrid

\section{Bibliografía}

1. Howden CW, Hunt RH. The relationship between suppression of acidity and gastric ulcer healing rates. Aliment Pharmacol Ther 1990; 4: 25-33.

2. Ramdani A, Mignom M, Samoyeau R. Effect of pantoprazole versus other proton pump inhibitors on 24-hour intragastric $\mathrm{pH}$ and basal acid output in Zollinger-Ellison syndrome. Gastroenterol Clin Biol 2002; 26: 355-9.

3. Hawkey CJ, Karrasch JA, Szczepanski L, et al and the Omeprazol versus Misoprostol for NSAID-Induced Ulcer Management (OMNIUM) study group. Omeprazol compared with misoprostol for ulcers associated with nonsteroidal antiinflammatory drugs. N Engl J Med 1998; 338: 727-34.

4. Yeomans ND, Tulassay Z, Juhasz, et al for the Acid Suppression Trial Ranitidine versus Omeprazole for NSAID-Associated Ulcer Treatment (ASTRONAUT) Study Group. A comparison of omeprazole with ranitidine for ulcers associated with nonsteroidal antiinflammatory drugs. $\mathrm{N}$ Engl J Med 1998; 338: 719-26.

5. Ofman JJ, Gralnek IM, Udani J, et al. The cost.effectiviness of the omeprazole test in patients with noncardiac chest pain. Am J Med
1999; 107: 219-27.

6. Lau J, Sung J, Lee K, et al. Effect of intravenous omeprazole on recurrent bleeding after endoscopic treatment of bleeding peptic ulcers. N Engl J Med 2000; 343: 310-6.

7. Lam NP, Le PD, Crawford SY, et al. National survey of stress ulcer prophylaxis. Crit Care Med 1999; 27: 98-103.

8. Noguerado Asensio A, Rodríguez Barrientos R, Zelaya Castro P, et al. Utilización de supresores de la secreción ácida en pacientes hospitalizados. An Med Interna (Madrid) 2002; 19: 557-560.

9. Morimoto T, Noguchi Y, Sakai T, et al. Acute pancreatitis and the role of histamine-2 receptor antagonists: a meta-analysis of randomized controlled trials of cimetidine. Eur J Gastroenterol Hepatol 2002; 14: 679-86.

10. Weekes LM, Brooks C, Day RO. Indicators for drugs and therapeutics commitees. Br J Clin Pharmacol 1998; 45: 393-8.

11. Nardino RJ, Vender RJ, Herbert PN. Overuse of acid-suppressive therapy in hospitalized patients. Am J Gastroenterol 2000; 95: 3118-22. 